\title{
Editorial
}

\section{Letter to the reader: 1986}

Despite the proliferation and most obvious well-being of diabetes-related journals and other publications hailed by some and lamented by others - the world of scientific editing appears to be experiencing a crisis of far-reaching consequences. On the one hand, the personal pride of the ever-increasing number of investigators, the increasingly competitive systems of research funding and academic promotion, and last, but probably most important, the economic pressures from the pharmaceutical and publishing industries have led to astronomical increases in the number of medical journals, books, symposia proceedings, publications and meetings. On the other hand, the average clinician/investigator complains more and more about being flooded and overwhelmed by information of dubious scientific standards and value. Thus, it is often stated that this proliferation of publications is counterproductive, since it is mostly unnecessary; one might be forced to waste increasing amounts of time and effort to identify those items which are really worth being read and discussed with colleagues and students. All of these problems and difficulties seem to be particularly pertinent to the field of diabetology. During the remaining 2 years of my tenure as editor of Diabetologia, I plan to use the forum of the "Letter to the Reader" from time to time to discuss some of these problems as they appear from the point of view of the editorial team.

Today I would like to focus upon two such problems, i.e. (1) the editorial difficulties with the increasing number of co-authors for scientific papers and (2) the rather dubious practice of publishing symposia proceedings. No doubt these problems are interrelated and, at the same time, part of the overall crisis of the proliferating publishing business/game and the questions of responsibility and fraud in science - items which are being discussed at present in many editorials and conferences throughout the various disciplines of science.

Like other journals, Diabetologia has experienced a steady and rather astonishing rise in the number of coauthors who are identified as contributors to original publications. A number of reasons have been put forward for this development, such as the increasing complexity of research and, more appropriately, the increasing desire of investigators to enlarge their publication lists. This strange ambition - be it justified by the equally strange habits of academic search committees or not - has not only led to absurd production rates of scientific publications in many instances and to the gradual lowering of the requirements for the least publishable unit (LPU), but - at the same time and much more dangerously - it has clouded the responsibility of being a co-author of a scientific contribution. It is no secret that all of the laboratories which later became known as the origin of fraud in science had been particularly successful in the publishing game in the years preceding these unfortunate incidents, with the principal investigator being the (senior) co-author of several hundred scientific publications within a few years. Suffice it to say that such productivity is bound to be incompatible with an active responsibility of the (senior) co-author concerning the scientific content of the flood of manuscripts leaving his laboratories. And yet, it remains undisputed that scientific progress does rely on the cooperation of investigators - on the team approach and on the intellectual interaction and practical collaboration of scientists, as Goethe stated so clearly in 1792 [1]. How often, however, have we all experienced the perturbation of any meaningful and sensible system of cooperation when it comes to "co-authorising" a manuscript. Not infrequently, individuals who have neither cooperated during nor been co-responsible for the investigation insist on being included as co-authors, whereas others are unjustifiably eliminated from the growing list of contributors. Often the discussions over who is to become a co-author have preoccupied and paralysed entire teams of investigators for quite some time. In his fictional essay, "Der Wiesbadener Kongress", Walter Vogt [2] describes a group of psychiatrists who have been asked to contribute a paper of their choice to an important medical congress. Even before they ever start to discuss the 
subject of their contribution, their conflicts over the list of co-authors and their eventual placement within this list becomes so intense that suicide and homicide take place amongst the potential investigators without the actual aims of the research project ever having been formulated. In practice, these controversies are - thank God - less dramatic, but often all the more amusing, at least for someone who is personally not involved.

In order to help the scientific community to end or avoid these fruitless discussions and arguments and, more importantly, to clearly define the responsibilities concerning a co-author's potential fame or blame, the International Committee of Medical Journal Editors [3] has proposed guidelines on co-authorship for scientific publications. Like other journals, Diabetologia has adopted these guidelines. As of 1 January 1987, its editorial board has decided that all contributing co-authors must - in addition to the certification of the article's originality [4] - sign the following statement acknowledging their specific justification and responsibility for co-authorship:

The undersigned confirm(s) that their (co-)authorship is based upon the following conditions:

1) Each author has participated sufficiently in the work represented by the article to take public responsibility for the content.

2) The participation must include conception or design of the work presented by the article and/or analysis and interpretation of the data and/or drafting the article or revising it for critically important content and final approval of the version to be published.

3) Participation solely in the collection of data or other evidence or financial resources does not justify authorship.

4) Each part of the content of an article to its main conclusions and each step in the work that led to the publication must be attributable to at least one author.

5) Persons who have contributed intellectually to the article but whose contributions do not justify authorship may be named and their particular contribution described. Such persons must give their permission to be named.

The editorial board welcomes any comments vis-à-vis this new editorial policy and will review its (side-)effects at its next regular meeting, which is scheduled to be held at the historical site of Auerbach's Keller in September 1987 in Leipzig.

A number of misunderstandings developed amongst the readership of Diabetologia when its editorial board decided to require a written statement for all manuscripts submitted as original communications. The statement certified that the content of the submitted article had never been published (nor was presently under review) elsewhere except in abstract form, i.e. less than 300 words. As stated quite explicitly [4], this statement had to include the denial of prior reports and symposia proceedings, monographs, etc. Nevertheless, some authors were surprised and disturbed when the editorial board began to enforce this policy, and a num- ber of manuscripts had to be rejected (primarily for the reason that essential parts of the information displayed in the article had previously been reported in a volume of symposium proceedings). In fact, the useless and counterproductive nature - except with regard to the personal pride of the editors and the sponsors, and the budget of the publisher - of these publications of symposia proceedings has been most vividly hallmarked by Mitchell $[5,6]$, who proposed the formation of an association of SWOPs (Speakers Who Oppose Publication). His description of the methods by which SWOPs can and are being turned into SWAPs (Speakers Who Approve Publication) was quite impressive. Inasmuch as we could probably all be encouraged to follow Dr. Mitchell's example of becoming SWOPs once and for all in order to help cut down on unnecessary and counterproductive publications, Diabetologia's editorial board consistently tries to discourage authors from quoting references from unreviewed publications such as symposia proceedings, and to use the over-abundant inflow of symposia proceedings (often sent to Diabetologia to be presented in our Book review section) to identify potential overlaps between those proceedings and manuscripts submitted as original papers.

In the long run and in accordance with the editors of comparable journals, we hope to be able to discourage the confusing proliferation of diabetes publications, to combat the slicing of studies into LPUs where one extensive publication should have been appropriate, to reduce the list of co-authors of questionable contribution and responsibility in order to increase the overall quality and significance of our articles, and to offer the readership a clear picture of who is to blame or to praise for their content.

In the hope of being able to depend upon the support of our readers in achieving these goals, I remain.

Yours sincerely,

Michael Berger

Editor-in-Chief

\section{References}

1. Goethe JW von (1792) Versuch als Vermittler von Objekt und Subjekt. In: Schriften zur Wissenschaftslehre

2. Vogt W (1972) Der Wiesbadener Kongress. Arche-Verlag, Zürich

3. Huth EJ (1986) Guidelines on authorship for medical papers. Ann Int Med 104: 269-274

4. Berger M (1984) A letter to our readers. Diabetologia 27: 1-2

5. Mitchell JRA (1983) Speakers of the world, unite! Br Med J 287: 418

6. Mitchell JRA (1983) A perspective on SWOP (Speakers who oppose publication) $\mathrm{Br}$ Med J 287: 1550-1551 